\title{
Self-efficacy latent growth trajectories' longitudinal links with achievement and interest: Both baseline and growth rate are important for interest outcomes
}

Luke K. Fryer, Faculty of Education (CETL), The University of Hong Kong, Hong Kong H. Nicholas Bovee, Kyushu Sangyo University, Japan

Nakao, K., Seinan Gakuin University, Japan

\section{Author Note}

Luke K. Fryer Đhttps://orcid.org/0000-0001-6250-5950

We have no known conflicts of interest to disclose.

Correspondence concerning this article should be addressed to Luke K Fryer, The University of Hong Kong, Pokfulam Rd. Centennial Campus, Hong Kong.

Email: lukefryer@yahoo.com

\section{Acknowledgements:}

We would like to extend our appreciation to Mary Ainley for reviewing an early version of this manuscript. This study was partial supported by a JSPS Fellowship grant (No. S20135) to the first author.

\section{Submitted version.}

Subsequently published in British Journal Educational Psychology:

Fryer, L. K., Bovee, H. N. \& Nakao, K. (in press). Self-efficacy latent growth trajectories' longitudinal links with achievement and interest: Both baseline and growth rate are important for interest outcomes. British Journal of Educational Psychology. http://doi.org/10.1111/bjep.12473

\section{PRE-PRINTED COPY}




\section{ABSTRACT:}

\section{Background:}

Self-efficacy has well established theoretical and empirical linkages to persistence and achievement. Budding theoretical and recent empirical research has worked to connect selfefficacy to students' interest. Building on research in these areas, burgeoning research has begun to examine the relative role of intercept and slope of self-efficacy for these learning outcomes.

\section{Aims:}

This study builds on and extends previous research by testing the longitudinal implications of self-efficacy's latent growth for knowledge and interest gains.

\section{Methods:}

These aims were addressed by testing a fully-forward, latent SEM which included a latent growth curve (self-efficacy for a course of study) framed by pre-post standardised tests and measures of individual interest in the domain. This research was undertaken in the motivationally challenging context of a compulsory foreign language university programme in western Japan. First and second year students from 10 faculties participated $(n=1184)$ across a single semester, resulting in seven separate data points.

\section{Result:}

The SEM confirmed the important longitudinal roles of self-efficacy intercept within achievement, and both intercept and slope within future interest. Findings support and extend recent latent curve analysis with similar variables, lending further support to the critical role played by self-efficacy within the development not only of knowledge, but of individual interest as a learning outcome. 


\section{Introduction}

To live is to learn; learning is quintessentially developmental. From walking and talking to making the perfect cup of coffee, our experiences yield a complex trajectory of object specific knowledge development. This trajectory is determined, to varying degrees, by a host of external and intra-individual factors. Few factors share as close a symbiotic relationship with knowledge development as interest. Interest is best defined as a desire to reengage with a specific object (Renninger \& Hidi, 2015). At interest's earliest stages of development, it can be characterized as a focusing of attention, as well as an emotional response that catches and holds us as we struggle to understand, solve, or find (Renninger \& $\mathrm{Su}, 2019)$. As knowledge of an object increases, interest can become a persistent desire to reengage (Renninger \& Hidi, 2015), which can in turn support the elaboration of our knowledge (Fives \& Dinsmore, 2017). This symbiotic growth makes interest as important an outcome of learning as knowledge itself. For educators, the important question therefore is: how is this paired growth supported? A substantial body of intervention research has focused on value as a critical fulcrum for raising interest (utility-value or internally regulated value depending on the theory: Canning et al, 2018; Hulleman et al, 2010, Harackiewicz et al., 2016; Harackiewicz, et al., 2012; Vansteenkiste, et al., 2006). However, research suggests that ability-beliefs might be an even stronger longitudinal predictor of interest. Consistent with self-efficacy's focus on persistence and grade goal-setting in educational settings (Bandura, 1993), self-efficacy has been found to be equally if not more important than value in educational settings, being a substantial predictor of achievement (Fryer \& Ainley, 2019; Nuutila, et al., 2021). Recent Latent Growth Curve research lends some support to this finding, with changes in ability-beliefs (expectancy in the case of Kosovich, et al., 2017), predicting both future interest and achievement more than utility-value. This growing body of empirical evidence supporting the important role of self-efficacy within interest is buttressed by longstanding theory suggesting that the two are reciprocally linked over time (Fryer $\&$ Ainley, 2019; Nuutila, et al., 2020). Due to interest's hypothesised developmental nature (Renninger \& Hidi, 2015), part of which is in tandem with increasing self-efficacy for interest's object, it is reasonable to suggest that the rate of self-efficacy's growth as well as its baseline will be an important longitudinal predictor of interest. 
The present study is a further examination of the critical factors that foster interest and knowledge development during formal education. We extend recent research in this area by testing the longitudinal, predictive strength regarding the latent growth of self-efficacy beliefs for individual interest and knowledge gain, adding the variable of persistence in a set of assigned course tasks as an additional observed outcome. Latent growth curves include two components: intercept (baseline) and growth (slope). The intercept refers to its initial level and slope refers to the trajectory from the initial level. The study was carried out across a 15-week (one semester), foreign language course at a Japanese university. This course, part of a two-year programme of compulsory foreign language courses, was similar to those taken by most first and second year Japanese students as part of their undergraduate requirements. This large-scale, motivationally challenging environment provided both a sample size large enough for complex Latent Growth Curve modelling and a diversity of student majors (from 10 faculties) that broadens the theoretical and practical contributions of our findings. Our results longitudinally confirm the centrality of baseline and growth rate self-efficacy beliefs for essential learning outcomes such as an increase in knowledge and greater interest in the domain of study.

\section{Background}

\subsection{Critical Role of Interest for Learning}

The four-phase model of interest development (Hidi \& Renninger, 2006; Renninger \& Hidi, 2020) serves as a comprehensive theoretical base from which we can construct hypotheses regarding the development of interest over time. The model conceptualizes interest development as progressing sequentially through four discrete phases which start with environmental triggers and move toward self-generated predispositions to seek reengagement. These phases are: (a) triggered situational interest, associated with externallytriggered changes in affect; (b) maintained situational interest, associated with increased external support for value for an object; (c) emerging individual interest, associated with a nascent self-generated proclivity to repeatedly reengage with an object; and (d) welldeveloped individual interest, associated with a growing sustainable self-generated desire to reengage with an object over longer time periods, potentially in the absence of external support.

Working alongside the development of the Four Phase Model, theory extending and connecting interest to important factors that influence interest have been substantiated. It is well established that the depth of an individual's knowledge grows through clear categorical 
stages of understanding as interest develops (Model of Domain Learning; Alexander, 2003). Self-efficacy is theorised as having a reciprocal relationship with interest (Hidi \& Ainley, 2008; Hidi, et al., 2006), with interest hypothesised as being the initial spark that kickstarts the growth process (Ainely, et al., 2009). Studies modelling knowledge and self-efficacy together with interest have confirmed the supportive role played by these individual differences in regard to interest as a learning outcome (see recent longitudinal research such as Hulleman et al, 2017; Grigg et al., 2018; Fryer \& Ainley, 2019; Fryer et al., 2021; Nuutila, et al., 2021). While longitudinal research has established the importance of individual differences such as self-efficacy for interest, less is known about the role of self-efficacy latent growth and interest development.

\subsection{Ability beliefs}

Ability-beliefs are recognised by most major motivational theories as being central to persistent engagement (e.g., perceived control, social cognitive theory, self-determination theory, control-value theory, expectancy-value theory; Skinner, 1995; Bandura, 1997; Ryan \& Deci, 1985; Pekrun; 2006; Feather, 1982). While constructs capturing different types of ability beliefs and perceptions of control abound (see Skinner 1996 for a succinct taxonomic review), reviews (Honicke \& Broadbent, 2016) and mounting meta-analytic evidence points to self-efficacy as perhaps the most important ability-belief correlate of achievement (Richardson, et al., 2012; Schneider et al., 2017).

Focusing specifically on interest, longstanding empirical findings confirm a robust relationship between self-efficacy and interest (e.g., Schunk \& Bandura, 1980). More recently, evidence supporting a persistent, longitudinal reciprocal relationship has begun to emerge (e.g., Fryer \& Ainley, 2019; Nuutila, et al., 2020). Recent studies with increasingly sophisticated research designs have added nuance suggesting that the reciprocal nature of this relationship might be context/domain specific (Lee \& Seo, 2020). Less research has examined the relationship of the slope and (versus) intercept of self-efficacy with future interest and achievement. Existing studies have indicated first that latent growth curves (usually assessed as expectancy rather than self-efficacy beliefs) tend, upon average, to indicate decreasing trends, but at rates that vary depending on the sample (Chouinard, et al., 2011; Jacobs et al., 2002; Kosovich et al., 2017). Examination of self-efficacy latent growth curves specifically has indicated substantial relationships with achievement (Nuutila, et al., 2021; Markku \& Tapola, 2007), but predictive relationships with interest as a learning outcome have yet to be tested. 


\subsection{Knowledge and Gender}

Reviews have consistently pointed to prior knowledge as one of, if not the most important individual difference brought to the learning experience. Prior knowledge can account for 30-60\% of the variance in future learning (Tobias, 1994). This is unsurprising, considering that learning processes often involve building on, and integrating new information into, prior knowledge (Dochy, 1992). Parallel to these findings, a meta-analysis has confirmed scholastic achievement as a strong covariate of interest (Schiefle, et al., 1993). Bringing these streams of research together, the Model of Domain Learning suggests that the more there is of prior knowledge and interest - and the greater their depth - the deeper new learning experiences can be (Fives \& Dinsmore, 2017).

The Four-Phase Model organises knowledge and interest as developing together across repeated engagements with an object (Hidi \& Renninger, 2006, Renninger \& Hidi, 2020). The link from prior knowledge to future interest has less often been tested. However, prior knowledge has generally been a consistent if small predictor of future interest in largescale latent longitudinal studies (Fryer et al., 2020, 2021; Fryer \& Ainley, 2019; Marsh 2005; Nuutila, et al., 2020).

Gender is an additional individual difference with established linkages to psychological factors related to learning outcomes (Voyer \& Voyer, 2014, Voyer et al., 2020). While this study does not specifically address gender, it is essential that it be controlled for when examining the longitudinal impact of motivation- and belief-related individual differences on learning outcomes.

\subsection{Current Study}

The current study builds on previous research focusing on the longitudinal role of self-efficacy (Fryer et al., 2021; 2019; 2016; Fryer \& Ainley, 2019; Griggs et al., 2018; Nuutila, et al., 2020; 2021) or expectancy (Kosovich et al., 2017; Robinson, et al., 2019; Nuutila, et al., 2018) within students' interest in a domain of study. These connections have theoretical implications for how interest and knowledge develop across the learning process, and they are of practical concern to educators seeking to support students' persistence and achievement across a wide variety of formal education experiences. A latent curve approach to estimating students' self-efficacy beliefs was undertaken as past evidence from pre/post standardised testing has suggested that students in this programme experience average increases in knowledge of more than 1/2 standard deviation each semester. Self-efficacy is a strong correlate of achievement suggesting that self-efficacy might also grow consistently. 
Aligned with recent related work in this general area (Kosovich et al., 2017; Nuutila; 2021; Robinson, et al., 2019), the present study focuses on the development of self-efficacy beliefs through longitudinal SEM which integrates latent growth curve analyses. The current study was therefore undertaken across one semester of a compulsory course in foreign language studies at one Japanese university. Due to the compulsory nature of the course, students representing a diverse range of initial interest and knowledge from across the university's 10 faculties participated in the study. Data was collected across 15 weeks, with pre-post measures of knowledge (standardised test and individual interest) framing three measures of self-efficacy. This design (Figure 1) enabled three research questions to be asked, and six hypotheses to be tested.

+++++++++++++++++++++++Figure 1 About Here++++++++++++++++++++++++++++

\section{Aims}

The present study aimed to clarify the relative longitudinal role of academic selfefficacy within student learning in a specific domain of study. To this end, while accounting for prior interest, knowledge, and gender, the relative strength of $\beta$ s from intercept and slope of the latent growth curve for self-efficacy beliefs to post interest and knowledge, as well as learner persistence (a series of e-learning assignments), were tested. The latent model test was longitudinal for interest in the domain, self-efficacy for the course, and knowledge of the domain. Learner persistence (i.e., e-learning assignments) was also included as a learning outcome. The model was tested fully-forward, with all prior variables predicting all future variables with no regression linkages removed to improve fit. Hypotheses set for linkages were supported by theory and prior research.

This study's research questions were posed on three foundational hypotheses: gender (Female) was expected to present small negative forward relationships with interest and selfefficacy (H1; Voyer \& Voyer, 2014) but with no other variables; prior knowledge was expected to have moderate to large relationships with all future constructs modelled $(\mathrm{H} 2$; Dochy, 1992; Schiefele, et al., 1993); prior interest was expected to predict self-efficacy (potentially both intercept and slope) and with post interest (Hidi \& Ainley, 2008), both interest measurements were expected to present small to moderate relationships with post knowledge and e-learning completion (H3; Fryer \& Ainley, 2019; Renninger \& Hidi, 2015).

The first research question addressed by this study was: what is the relative longitudinal relationship from self-efficacy (intercept and slope) for future knowledge gain (Research Question one; RQ1)? Past studies (Fryer \& Ainley, 2019; Kosovich et al., 2017) 
support the contention that self-efficacy will predict knowledge gains across a course of study (H4). The second question addressed by the current study considers the relative relationship of self-efficacy (intercept and slope) with interest gains across a course of study (RQ2). Past empirical research (Fryer \& Ainley, 2019) and the developmental nature of interest (Hidi \& Renninger, 2006) suggest that self-efficacy will be at least a moderate predictor of increasing interest (H5). While not directly transferable to hypotheses in this study, similar SEM analysis with slope and intercept for expectancy (a limited proxy for self-efficacy) suggest only that the slope (not intercept) for self-efficacy might be a strong predictor of post interest (Kosovich, et al., 2017). Whether this holds true for self-efficacy is an open question.

The final question is concerned with the relationship between academic self-efficacy and persistence in a specific, assigned learning activity (a series of e-learning assignments) (RQ3). Given self-efficacy's theoretical and empirical linkages to behavioural persistence (Bandura, 1993), it is reasonable to expect a positive relationship for self-efficacy with the completion of learning assignments, but not enough evidence exists to suggest its potential strength or whether both intercept and slope will contribute (H6).

\section{Methods}

\subsection{Participants}

The present study was undertaken with a randomly selected split-half group of firstand second-year students attending a university in western Japan (sample analysed for this study: $n=1184$; female $=322$ ) completing a two-year programme of compulsory English as a foreign language as part of a four-year degree (Fryer, et al., 2010). The gender balance of the sample was consistent with the university as a whole. Students were invited to participate in the research from within their weekly e-learning assignments for their English as a foreign language courses based on their student number. Informed consent from the students (ages 18-20) was received prior to proceeding. A small percentage of the students opted not to participate in the research at some point during the project $(n=80)$ and were removed from this study's analyses. The Language Education and Research Centre at which the study was conducted reviewed and granted ethical approval for it to proceed.

\subsection{Procedures}

Surveys for the current study were administered within the students' compulsory elearning (Fryer \& Bovee, 2011), one of many course components shared by all foreign language courses (e.g., curricula, textbooks, e-learning, and assessments across all participating courses; Fryer et al., , 2010; Stewart et al., 2012; 2013). This e-learning took 
approximately one hour per week to complete as homework and was typically accessed by students on their smartphones. Students could opt out of the study at any time by checking a box in the online surveys. Roughly half of the students in 48 classes were randomly selected (based on the last number of their student number: even/odd) to receive an invitation to participate in the study (evenly divided between first- and second-year classes). The timing of the measurements taken across a single semester of classes (15-weeks) is presented in Figure 1.

The sample used in the current study formed the control group (random split-half) from a previous experimental study $(n=2389)$ where utility-value was also assessed. It is a random sample of roughly $80 \%$ of the university's first- and second-year population. Although pre-post interest and knowledge measures were employed in the previous study, the longitudinal self-efficacy constructs were not. These constructs are the focus of the current study.

\subsection{Instruments}

Data collection for the present study focused on a combination of self-report (course self-efficacy, and individual interest), standardised testing of students' English language knowledge, and e-learning assignment completion. Prior knowledge and post knowledge of English were tested employing a standardised test of English listening and reading skills (Stewart et al., 2013; 2012 ). This 60-minute test was administered to all students in the twoyear programme of compulsory English as a foreign language course. The pre-test was used to assign students to appropriate level classes at the beginning of the year. A second test administered at the end of the term comprised $20 \%$ of the students' semester grade.

At the beginning and end of the academic semester, a self-report survey was administered to assess student interest in learning English as a foreign language. At three times between the beginning and end points, students' self-efficacy for the course of study was collected. The interest scale consisted of three items (e.g., "I am interested in learning English”) from Ichihara and Arai (2004). Self-efficacy was measured using five items (e.g., "I can do almost all the work in this class if I don't give up") from the Patterns of Adaptive Learning Scales (Midgley et al., 2000). All items were self-reported across a cumulative scale from one (not at all like me) to six (exactly like me). The surveys are presented in Table 1 in the Appendix (original English and the Japanese translations). 


\subsection{Analyses}

Data analysis proceeded in three stages, with the first two stages establishing a base for the third wherein the study's research questions and hypotheses were addressed. First, invariance testing, then construct validity was assessed with a configural CFA of all constructs together, followed by reliability analysis of the self-reported constructs (Cronbach's Alpha). All Structural Equation Modelling was undertaken using the Maximum Likelihood Robust algorithm native to Mplus 7.1. Second, descriptive statistics and pairwise correlations were calculated and briefly reviewed, with differences across time examined through ANOVA and pairwise Tukey-Kramer HSD. Third, individual structural equation models (SEM) were generated which included configural and then invariance (metric and scalar) tests for longitudinal latent variables (interest and self-efficacy); this was followed by unconditional and conditional latent growth curve tests. Finally, the full SEM, which was included in the LCA (Slope and Interest correlation was constrained to 0) was tested. All latent analyses were conducted using Mplus 8, while reliability and descriptive statistics were conducted using JMP 14.1.

The SEMs were assessed for fit to the data using four well-known indices: Root Mean Square Error of Approximation (RMSEA), with values < .08 and .05 indicating acceptable and good fit respectively (Browne \& Cudeck, 1992), Tucker Lewis Index/Confirmatory Fit Index (TLI/CFI) with values above .90 and .95 indicating acceptable and good fit respectively (Marsh et al., 1988).

Invariance testing was conducted for each pre-post individual interest and the latent curve variables (self-efficacy and value) in three stages: Configural, Metric and Scalar. Marsh et al.'s (2013) example was followed wherein CFI and RMSEA comparisons are used to test the assumption of invariance of construct across the semester-long study. Chen (2007) contended that the assumption of invariance is tenable if the CFI does not change by greater than .01 and the RMSEA increases by no more than .015 for the invariant model.

Missing data was negligible $(<1 \%)$ and handled by imputing the dataset through utilising the Robust Expected Maximum Likelihood Algorithm native to JMP 14.01.

\section{$5 \quad$ Results}

\subsection{Construct validity, pairwise correlations, reliability, descriptive statistics, and difference tests}

Stage 1: Invariance testing for the longitudinal latent variables, consistent with Chen's (2007) guidelines, suggested that the assumption of invariance was tenable for self-efficacy 
across one semester. Chen's (2007) heuristic suggested that invariance for interest was not tenable (RMSEA for Scalar invariance). It is reasonable, however, given the inherently developmental (and therefore changing) nature of interest (Hidi \& Renninger, 2006; Renninger \& Hidi, 2015), that the strictest invariance (scalar tests) be loosened to fit the growth and development of students' interest.

A configural Confirmatory Factor Analysis (CFA) of all variables modelled resulted in good fit (Table 2). Pairwise correlations and Cronbach's Alphas were consistent with theory and past empirical findings with these constructs (Table 3). Together, these results indicated sufficient convergent and divergent validity for the study's measures.

$=$ Table 2 and 3 ABOUT HERE

Stage 2: Mean differences across the three time points for self-efficacy (time points IV and latent constructs DV) indicated no significant difference for self-efficacy (F $(1182)=.911, p=.402)$. A pairwise test of pre-post interest indicated a small statistically significant decrease in interest $(\mathrm{T} 1$, mean $=4.61, \mathrm{SD}=1.43$; $\mathrm{T} 2$ mean $=4.43, \mathrm{SD}=1.38 ; t=18.26$, $\mathrm{df}=11183, p=.001$, Cohen's $d=.17)$.

\subsection{Latent Growth Analysis and final SEM (Stage 3)}

Invariance tests for each interest and self-efficacy suggested invariance was tenable for all longitudinal variables (Table 4). Un/conditional LGCs were then tested, confirming that Intercept $($ mean $=3.81$, Standard Error $=.23)$ and Slope $($ mean $=-.40$,

Standard Error $=.33$ fit best.

$=$ Table 4 ABOUT HERE

The full longitudinal SEM (RQ1-3, H1-6) was tested, including the LGC, gender, prep-post interest, pre-post knowledge and e-learning. This resulted in good fit: CFI/TLI $=.96 / .94$, RMSEA=.056 (CI 90\% .05-.06), $X^{2}=382.072$ (82). Figure 2 presents the SEM results in full, with no paths removed to improve fit. The

The results of the SEM test are presented consistent with the order of the preliminary hypotheses $(\mathrm{H} 1-\mathrm{H} 3)$ for the control variables. This presentation is followed by questions and hypotheses (H4-H6) regarding self-efficacy's (intercept and slope) longitudinal relationship with each post knowledge (RQ1), interest (RQ2), and then learning persistence as a learning outcome (RQ3).

Addressing the controls first, Gender (female/male=0/1) presented no statistically significant relationships with any other modelled variable (H1). Prior knowledge presented 
five statistically significant $\beta \mathrm{s}(\mathrm{H} 2)$ : medium prior interest $(\beta=.17)$; large post knowledge $(\beta=.45)$; medium and small for self-efficacy intercept $(\beta=.15)$ and self-efficacy slope $(\beta=.08)$ respectively; and medium for e-learning completion $(\beta=.22)$. Prior interest presented medium $(\beta=.22)$ and large $(\beta=.60)$ statistically significant $\beta$ s for post interest and self-efficacy intercept respectively (H3).

RQ1, H4: Self-efficacy slope presented no statistically significant relationship with post knowledge. In contrast, self-efficacy intercept presented a moderate relationship with post knowledge $(\beta=.20)$.

RQ2, H5: Self-efficacy slope and intercept each presented a large significant relationship with post interest $(\beta=.54 ; \beta=.47)$.

RQ3, H6: Neither slope nor intercept for self-efficacy predicted e-learning completion with statistical significance.

\section{Discussion}

Following invariance testing for the longitudinal variables, a configural model was tested, confirming convergent and divergent validity of modelled constructs. Pairwise correlations and reliability (for latent constructs) were consistent with past research in this area. Difference testing confirmed no statistically significant difference for self-efficacy across the study. Latent Curve Analysis comparing intercept with intercept/slope confirmed better fit for intercept/slope modelling.

After controlling for gender, prior interest, and knowledge, the present study tested the relative longitudinal impact of self-efficacy trajectories (slope and intercept) on future interest and knowledge increase, and on e-learning assignment completion, across a 15-week semester of a compulsory foreign language course. To this end, three research questions and six hypotheses were tested. Prior to these tests, invariance, reasonable reliability, and construct validity were confirmed. Mean difference testing indicated small decreases in interest across the study, but no significant change in self-efficacy beliefs on average.

\subsection{Research Questions and Hypotheses}

H1: Expectations regarding gender's role was not statistically significant for either self-efficacy (intercept and slope) or interest.

$\mathrm{H} 2$ : Prior knowledge was, as expected, a strong predictor of nearly all forward variables. Its large impact on post knowledge was to be expected, but it was also the sole statistically significant predictor of e-learning completion. Prior knowledge played important 
roles within interest (prior) and self-efficacy (intercept) as well, confirming its critical role within learning experiences and outcomes.

H3: Prior interest, while presenting a medium relationship with post interest, failed, along with post interest, to present statistically significant forward connections to post knowledge or e-learning completion.

RQ1 and H4: Supporting H4, structural modelling indicated that future knowledge was positively predicted by self-efficacy, but only by intercept and not slope. These results partially confirm past research pointing to self-efficacy as being a critical individual difference for knowledge gain (Honicke \& Broadbent, 2016; Richardson et al., 2012). The lack of statistically significant connection from slope might be due to the limited amount of time (13 weeks), the strict modelling controls employed and the standardised nature of the test, making the test disconnected from course curricula which students' growing self-efficacy was based on.

RQ2 and H5: Broadly supporting H5, self-efficacy beliefs were a substantial predictor, with both intercept and slope presenting large relationships with future interest. Both of these relationships were larger than prior interest, demonstrating how important initial and growing confidence in one's ability to be successful is for learning. These results support and expand on Bandura's (1993) theoretical and more recent empirical, longitudinal static findings (Fryer et al., 2016; 2021; Fryer \& Ainley, 2019; Nutilla, et al., 2020; 2021), which point to the centrality of self-efficacy for students' desire to reengage with a domain as well as for knowledge gains.

RQ3 and H6: Expectations that self-efficacy beliefs (intercept and slope) would present statistically significant linkages with the e-learning assignment completion were not supported. This signals that either self-efficacy is not a meaningful predictor for this kind of persistence, or that its impact was through post knowledge whose mediation could not be tested due to the sequential ordering of the model. Additional reasons for the lack of direct statistically significant effect were existing strong curricular supports for e-learning completion: grades, automated contact from the system and instructors who were encouraged to ensure students completed the assigned e-learning curriculum.

\subsection{Implications for theory}

A central theoretical question behind the current study was: how do self-efficacy beliefs' baseline and growth rate contribute to interest in and knowledge of a domain of study? In the present controlled, longitudinal study, self-efficacy beliefs' baseline and rate of 
growth were both medium to large predictors of both learning outcomes. Self-efficacy growth rate was the overall largest predictor of future interest, larger even than prior interest. The importance of self-efficacy growth rate is consistent with past expectancy-based curve findings (Kosovich, et al., 2017), supporting their contention that growing ability-beliefs is a crucial lever for both learning outcomes. At the same time however, the prominent role of self-efficacy growth rate within interest as a learning outcome highlights the under-theorised role of the growth rate of individual differences like self-efficacy beliefs within learning outcomes. Despite this empirical support, the fact is that none of our available related theories (i.e., social cognitive theory, expectancy value theory, or the four-phase model of interest) provide clear direction regarding how the rate of changing ability beliefs might impact learning outcomes.

At present, each of these theories takes a slightly different tack on what drives interest and knowledge growth; none of them offer a particularly satisfying explanation in the context of latent growth curve findings. EVT proposes that interest is just one kind of value, and that expectancy and value come together to determine choice, driving behavior and thereby relevant outcomes (Feather, 1982). A recent SEM study integrating latent curve analysis has suggested that expectancy slope might be the more important lever for interest growth (Kosovich, et al., 2017). Interest research working within the Four Phase Model framed interest development/growth and knowledge growth as being integral, connected processes, with self-efficacy acting as an important reciprocal driver of both (Ainley et al., 2009; Hidi et al., 2006). Social-cognitive theory (Bandura, 1986; 1997) presents self-efficacy as sustaining engagement and thereby supporting knowledge outcomes. However, the theory fails to draw clear theoretical lines to interest as a learning outcome. The only theoretical perspective which even alludes to growth in any clear manner is the four-phase model, which suggests that an individual's growth in value and knowledge play central roles within the qualitative development of (object specific) interest. The four-phase model is, however, less clear on the role played by the development of ability-beliefs such as self-efficacy. We suggest that each of these theories, and other major motivational theories such as SDT, need to return to their models to address how both growth and baseline for their central constructs might differentially function, and how they together/separately impact important learning outcomes like interest and knowledge. 


\subsection{Implications for practice}

The current study confirms considerable past research pointing to the important role of self-efficacy beliefs for interest and knowledge as learning outcomes (e.g., Fryer \& Ainley, 2019; Kosovich, et al., 2017). Students need to feel that they have the ability to successfully engage in their current subject (K-12) or course (tertiary). There is a substantial body of literature arising from multiple theories/models (SDT; UVT; Four Phase Model) that support educators in making and framing curricula so as to foster interest through supporting students' value beliefs. However, there is less research to draw upon to support educators in fostering interest through bolstering students' self-efficacy beliefs for a course of study. Bandura's (1977) well-cited social-cognitive modelling suggestions are of limited assistance in many classrooms. Like many other ability-belief constructs, self-efficacy is a perceived control construct (Skinner, 1996). It is therefore appropriate to draw upon perceived control theory (Skinner, 1995) to connect the instructional environment to students' beliefs (i.e., Structure). Although the concept of structure has been employed within SDT for decades (e.g., Jang et al., 2010; Skinner \& Belmont, 1993), it has only seen limited use firmly outside of this framework (e.g., Fryer \& Bovee, 2020). As an important contributor to students' experiences of teaching quality, it has been shown to be an important factor for self-efficacy development (Fryer \& Oga-Baldwin, 2019). Perceived control theory suggests that wellstructured teaching makes contingency in a learning environment clear; furthermore, wellstructured teaching transmits high expectations to students and provides understandable feedback about progress (Skinner, 1995). Such instructional supports are broadly consistent with views on how self-efficacy is suggested to function in educational environments (Bandura, 1993).

While the overwhelming importance of self-efficacy beliefs for future interest was demonstrated as the focus of this study, self-efficacy baseline was also found to be a robust predictor of achievement. This is consistent with meta-analyses (e.g., Richardson et al., 2012; Schnieder et al., 2017) that have pointed to the substantial contribution of self-efficacy beliefs to achievement for some time. Furthermore, multiple, recent controlled longitudinal latent studies have (Griggs et al., 2017; Fryer \& Ainley, 2019; Fryer et al., 2021) and continue (Nutilla et al., 2020) to confirm self-efficacy's importance for learning. The present study and the research it builds on (Kosovich et al., 2017) point to an additional role played by the growth of self-efficacy during sustained learning experiences (e.g., a course). From a practical perspective, students' desire to engage (and reengage) is largely dependent on a growing feeling that they are in greater control of curriculum content and are prepared for 
assessments (Skinner, 1995). This growth in perceived control is built, in part, on students having a strong understanding of a course's aims and its assessments. It is also dependent on feedback supporting students' sense of contingency in the learning environment as well as students' expanding perceived and actual knowledge of the curricula being studied (Skinner, 1995). Many curricular factors can enhance students' experiences along these lines. Strong starting points for enhancing curricula include instructional factors such as teacher clarity, feedback, and regular formative testing (Hattie, 2015). At a broader level, course organisation within a framework like outcome-based learning (e.g., Biggs, 2003) should be considered.

\section{$7 \quad$ Limitations and Future Directions}

Like all research of this kind, the present study is limited by its context. While it does build on and lend support to previous tertiary research, albeit with very different students, it is still one modest step towards clear external validity. Additional research in both optional and compulsory tertiary courses as well as research at other levels of formal education are needed to confirm the pattern of findings emerging from studies in this area. In addition to levels of education, a wide range of learning domains should be examined and compared, preferably intra-individually to examine how these processes play out for the same individual in different contexts (e.g., Fryer \& Oga-Baldwin, 2019).

\section{Conclusions}

The results of this study lend support to theory and burgeoning empirical evidence pointing to the importance of self-efficacy for increasing interest as a learning outcome. This study buttresses past related research (i.e., with expectancy; Kosovich et al., 2017), confirms self-efficacy's robust role within knowledge related outcomes, and highlights the substantial specific role of self-efficacy growth rate within increased interest in a study domain. These results have the potential to focus greater attention on the need to develop a more nuanced theoretical explanation for how self-efficacy influences students' learning and their interest across a course of study. Both educators and theorists must seriously consider not merely the degree to which self-efficacy is necessary, but also how self-efficacy changes (and can be supported to continue to change) across an extended series of learning experiences. 


\section{References}

Ainley, M., Buckley, S., \& Chan, J. (2009). Interest and efficacy beliefs in self-regulated learning. In M. Wosnitza, S. Karabenick, A. Efklides, \& P. Nenniger (Eds.). Contemporary motivation research: From global to local perspectives (pp. 207-228). .

Bandura, A. (1986). Social foundations of thought and action: A social cognitive theory. New York: Pearson.

Bandura, A. (1993). Perceived self-efficacy in cognitive development and functioning. Educational Psychologist, 28(2), 117-148. http://doi.org/10.1207/s15326985ep2802_3

Bandura, A. (1997). Self-efficacy: The exercise of control. New York: Freeman.

Bandura, A. (1977). Self-efficacy - toward a unifying theory of behavioral change. Psychological Review, 84, 191-215. doi:10.1016/0146-6402(78)90002-4

Biggs, J. B. (2003). Teaching for Quality Learning at University. Buckingham: Society for Research into Higher Education, Open University Press.

Bovee, H., \& Fryer, L. K. (2011). オンライン CALL システムに関する開発経過報 告。九州 産業大学 COMMON. Permanent Online Location :http://ci.nii.ac.jp/naid/ 40019173226.

Browne, M. W., \& Cudeck, R. (1992). Alternative ways of assessing model fit. Sociological Methods \& Research, 21, 230-258. https://doi.org/10.1177/0049124192021002005.

Canning, E. A., Harackiewicz, J. M., Priniski, S. J., Hecht, C. A., Tibbetts, Y., \& Hyde, J. S. (2018). Improving performance and retention in introductory biology with a utilityhttps://doi.org/10.1037/edu0000244

Chen, F. F. (2007). Sensitivity of goodness of fit indexes to lack of measurement invariance. Structural Equation Modeling, 14, 464-504. https://doi.org/10.1080/10705510701301834.

Chouinard, R., Karsenti, T., \& Roy, N. (2011). Relations among competence beliefs, utility value, achievement goals, and effort in mathematics. British Journal of Educational Psychology, 77(3), 501-517. http://doi.org/10.1348/000709906X133589

Deci, E. L., \& Ryan, R. M. (1985). Intrinsic motivation and self-determination in human behavior. New York: Plenum.

Dochy, F. J. R. C. (1992). Assessment of prior knowledge as a determinant for future learning: The use of prior knowledge state tests and knowledge profiles. Centre for Educational Technology and Innovation, Open University. 
Fryer, L. K., Anderson, C. J., Stewart, J., Bovee, H. N., \& Gibson, A. (2010). Coordinating a vocabulary curriculum: Exploration, pilot, trial and future directions. Paper presented at the The Japan Association for Language Teaching National Conference, Nagoya, Japan.

Fryer, L. K., Ainley, M. \& Thompson, A. (2016). Modelling the links between students' interest in a domain, the tasks they experience and their interest in a course: Isn't interest what university is all about? Learning and Individual differences. 50, 57-165 https://doi.org/ 10.1016/j.lindif.2016.08.011

Fryer, L. K. \& Ainley, M. (2019). Supporting interest in a study domain: A longitudinal test of the interplay between interest, utility-value, and competence beliefs. Learning and Instruction. 60, 252-262. https://doi.org/10.1016/j.learninstruc.2017.11.002

Fryer, L. K. \& Oga-Baldwin, W. (2019). Succeeding at junior high school: Students' reasons, their reach and the teaching that $\mathrm{h}$ (inders)elps their grasp. Contemporary Educational Psychology. 59. https://doi.org/10.1016/j.cedpsych.2019.101778

Fryer, L. K. \& Bovee, H. N. (2020). Teaching for course interest. Studies in Higher Education. 46, 2122-2133. https://doi.org/10.1080/03075079.2020.1712692

Fryer, L. K., Thompson, A., Nakao, K., Howarth, M., \& Gallacher, A. (2020). Supporting self-efficacy beliefs and interest as educational inputs and outcomes: Framing AI and Human partnered task experience. Learning and Individual Differences. https://doi.org/10.1016/j.lindif.2020.101850

Fryer, L. K., Shum, A., Lee, A. \& Lau, P. (2021). Mapping students' interest in a new domain: Connecting prior knowledge, interest, and self-efficacy with interesting tasks and a lasting desire to reengage. Learning and Instruction. https://doi.org/10.1016/ j.learninstruc.2021.101493

Feather, N. T. (1982). Expectations and actions: Expectancy-value models in psychology. Lawrence Erlbaum.

Grigg, S., Perera, H. N., McIlveen, P., \& Svetleff, Z. (2018). Relations among math selfefficacy, interest, intentions, and achievement_A social cognitive perspective. Contemporary Educational Psychology, 53, 73-86. http://doi.org/10.1016/j.cedpsych.2018.01.007

Harackiewicz, J. M., Rozek, C. S., Hulleman, C. S., \& Hyde, J. S. (2012). Helping parents to motivate adolescents in mathematics and science an experimental test of a utilityvalue intervention. Psychological Science. 
Harackiewicz, J. M., Smith, J. L., \& Priniski, S. J. (2016). Interest Matters: The Importance of Promoting Interest in Education. Policy Insights From the Behavioral and Brain Sciences, 1-8. http://doi.org/10.1177/2372732216655542

Hattie, J. (2015). The applicability of Visible Learning to higher education. Journal of Educational Psychology, 1, 79-91. http://doi.org/10.1037/st10000021

Hidi, S., \& Renninger, K. (2006). The four-phase model of interest development. Educational Psychologist, 41, 111-127. https://doi.org/10.1207/s15326985ep4102_4

Hidi, S., Ainley, M., Berndorff, D., \& Del Favero, L. (2006). The role of interest and selfefficacy in science-related expository writing. Writing and Motivation, 203.

Hidi, S., \& Ainley, M. (2008). Interest and self-regulation: Relationships between two variables that influence learning. In D. H. Schunk, \& B. J. Zimmerman (Eds.). Motivation and self-regulated learning: Theory, research, and applications (pp. 77109). Mahwah, NJ: Lawrence Erlbaum Associates.

Honicke, T., \& Broadbent, J. (2016). The influence of academic self-efficacy on academic performance: A systematic review. Educational Research Review, 17, 63-84. https:// doi.org/10.1016/j.edurev.2015.11.002

Hulleman, C. S., Godes, O., Hendricks, B. L., \& Harackiewicz, J. M. (2010). Enhancing interest and performance with a utility value intervention. Journal of Educational Psychology, 102, 880-895. https://doi.org/10.1037/a0019506

Jacobs, J. E., Lanza, S., Osgood, D. W., Child, J. E., 2002. (2002). Changes in children's selfcompetence and values: Gender and domain differences across grades one through twelve. 73, 509-527. http://doi.org/10.1111/1467-8624.00421

Jang, H., Reeve, J., \& Deci, E. L. (2010). Engaging students in learning activities: It is not autonomy support or structure but autonomy support and structure. Journal of Educational Psychology, 102(3), 588-600. http://doi.org/10.1037/a0019682

Kosovich, J. J., Flake, J. K., \& Hulleman, C. S. (2017). Short-term motivation trajectories: A parallel process model of expectancy-value. Contemporary Educational Psychology, 49, 130-139.doi:https://doi.org/10.1016/j.cedpsych.2017.01.004

Lee, Y.-k. and Seo, E. (2020), Longitudinal relations between South Korean adolescents' academic self-efficacy and values in mathematics and English. British Journal of Educational Psychology. https://doi.org/10.1111/bjep.12357

Marsh, H. W., Balla, J. R., \& McDonald, R. P. (1988). Goodness-of-fit indexes in confirmatory factor analysis: The effect of sample size. Psychological Bulletin, 103, 391. https://doi.org/10.1007/BF01102761 
Marsh, H. W., Nagengast, B., \& Morin, A. J. S. (2013). Measurement invariance of big-five factors over the life span: ESEM tests of gender, age, plasticity, maturity, and la dolce vita effects. Developmental Psychology, 49, 1194-1218. https://doi.org/10.1037/ a0026913.

Marsh, H. W., Trautwein, U., Lüdtke, O., Köller, O., \& Baumert, J. (2005). Academic selfconcept, interest, grades, and standardized test scores: Reciprocal effects models of causal ordering. Child Development, 76, 397-416. https://doi.org/10.1111/j.14678624.2005.00853.x.

Nuutila, K., Tapola, A., Tuominen, H., Molnár, G., \& Niemivirta, M. (2021). Mutual relationships between the levels and changes in interest, self-efficacy, and perceived difficulty during a task. https://doi.org/10.31234/osf.io/pd528

Nuutila, K., Tapola, A., Tuominen, H., Kupiainen, S., Pásztor, A., \& Niemivirta, M. (2020). Reciprocal Predictions Between Interest, Self-Efficacy, and Performance During a Task. Frontiers in Education, 5 (36 https://doi.org/10.3389/feduc.2020.00036

Nuutila, K., Tuominen, H., Tapola, A., Vainikainen, M.-P., \& Niemivirta, M. (2018). Consistency, longitudinal stability, and predictions of elementary school students' task interest, success expectancy, and performance in mathematics. Learning and Instruction, 56, 73-83. https://doi.org/10.1016/j.learninstruc.2018.04.003

Pekrun, R. (2006)The Control-Value Theory of Achievement Emotions: Assumptions, Corollaries, and Implications for Educational Research and Practice. Educational Psychology Review 18, 315-341. https://doi.org/10.1007/s10648-006-9029-9

Renninger, K. A., \& Hidi, S. E. (2020). To Level the Playing Field, Develop Interest. Policy Insights from the Behavioral and Brain Sciences, 7, 10-18. doi:10.1177/2372732219864705

Renninger, K. A., \& Su, S. (2019). Interest and Its Development, Revisited. In R. M. Ryan (Ed.), The Oxford Handbook of Human Motivation (pp. 205 -225). Oxford, England: Oxford University Press.

Renninger, K. A., \& Hidi, S. (2015). The power of interest for motivation and engagement: Routledge.

Renninger, K., \& Hidi, S. (2011). Revisiting the conceptualization, measurement, and generation of interest. Educational Psychologist, 46, 168-184. https://doi.org/10.1080/00461520.2011.587723

Robinson, K. A., Lee, Y. K., Bovee, E. A., Perez, T., Walton, S. P., Briedis, D., \& Linnenbrink-Garcia, L. (2019). Motivation in transition: Development and roles of 
expectancy, task values, and costs in early college engineering. Journal of Educational Psychology, 111, 1081-1102. http://doi.org/10.1037/edu0000331

Richardson, M., Abraham, C., \& Bond, R. (2012). Psychological correlates of university students' academic performance: A systematic review and meta-analysis. Psychological Bulletin, 138(2), 353-387. http://doi.org/10.1037/a0026838

Schneider, M., \& Preckel, F. (2017). Variables associated with achievement in higher education: A systematic review of meta-analyses. Psychological Bulletin, 143(6), 565-600 https://doi.org/10.1037/bu10000098

Skinner, E. A., \& Belmont, M. J. (1993). Motivation in the classroom: Reciprocal effects of teacher-behavior and student engagement across the school year. Journal of Educational Psychology, 85, 571-581. doi:10.1037//0022-0663.85.4.571

Skinner, E. A. (1995). Perceived control, motivation, \& coping (Vol. 8). Sage.

Skinner, E. A. (1996). A guide to constructs of control. Journal of Personality and Social Psychology, 71, 549-570. doi:10.1037/0022-3514.71.3.549

Stewart, J., Gibson, A., \& Fryer, L. K. (2012). Examining the reliability of a TOEIC Bridge practice test under 1 and 3 parameter item response models. Shiken research bulletin. 16. Retrieved from teval.jalt.org/sites/teval.jalt.org/files/SRB-16-2-Full.pdf.

Stewart, J., Fryer, L. K., \& Gibson, A. (2013). Assessing the dimensionality of three hypothesized sub-skills of L2 vocabulary proficiency. JACET JOURNAL, 51, 51-71. Retrieved from http://ci.nii.ac.jp/naid/110009597363.

Tobias, S. (1994). Interest, prior knowledge, and learning. Review of educational Research, 64(1), $37-54$.

Vansteenkiste, M., Lens, W., \& Deci, E. (2006). Intrinsic versus extrinsic goal contents in selfdetermination theory: Another look at the quality of academic motivation. Educational Psychologist, 41(1), 19-31. https://doi.org/10.1207/s15326985ep4101_4

Voyer, D., \& Voyer, S. (2014). Gender differences in scholastic achievement: A meta-analysis. Psychological Bulletin, 140, 1174-1204. https://doi.org/10.1037/a0036620

Voyer, D., Saint-Aubin, J., Altman, K., \& Doyle, R. A. (2020). Sex differences in tests of mental rotation: Direct manipulation of strategies with eye-tracking. Journal of Experimental Psychology: Human Perception and Performance, 46, 871889. https://doi.org/10.1037/xhp0000752 
10 TABLES and FIGURES

Table 2. Fit statistics for Structural Equation Models

\begin{tabular}{lll}
\hline & Full Latent Growth Model SEM & Full Configural Latent Model CFA \\
\hline CFI & 0.989 & 0.982 \\
TLI & 0.982 & 0.978 \\
RMSEA & 0.030 ( C.I. .023-.037) & 0.029 (C.I. .039-.045) \\
CHIsq & 132.469 (65) & $446.648(229)$ \\
\hline
\end{tabular}

Table 3. Invariance Testing Results

\begin{tabular}{|c|c|c|c|c|c|c|c|}
\hline & Self-efficacy & & Self-efficacy & & & & \\
\hline & CONFIGURAL & Self-efficacy Metric & Scalar & & Interest Config & Interest Metric & Interest Scalar \\
\hline CFI & 0.968 & 0.968 & 0.965 & CFI & 0.994 & 0.990 & 0.980 \\
\hline TLI & 0.959 & 0.962 & 0.963 & TLI & 0.990 & 0.990 & 0.980 \\
\hline RMSEA & 0.054 & 0.052 & 0.051 & RMSEA & 0.033 & 0.033 & 0.052 \\
\hline SRMR & 0.023 & 0.024 & 0.026 & SRMR & 0.011 & 0.022 & 0.036 \\
\hline CHIsq & $218.61(51)$ & $227.794(56)$ & $246.760(62$ & Chi-Square & $34.064(15)$ & $39.129(17)$ & $83.616(20)$ \\
\hline
\end{tabular}


Table 3. Pairwise correlations, descriptive statistics and Cronbach's Alpha for self-report scales

\begin{tabular}{|c|c|c|c|c|c|c|c|c|}
\hline & $\begin{array}{l}\text { Pre- } \\
\text { knowledge }\end{array}$ & Sex & $\begin{array}{l}\text { Interest } \\
\mathrm{T} 1\end{array}$ & $\begin{array}{l}\text { Self-Ef } \\
\text { T2 }\end{array}$ & $\begin{array}{l}\text { Self-Ef } \\
\text { T3 }\end{array}$ & $\begin{array}{l}\text { Self-Ef } \\
\text { T4 }\end{array}$ & $\begin{array}{l}\text { Interest } \\
\text { T5 }\end{array}$ & $\begin{array}{l}\text { Post- } \\
\text { Knowledge }\end{array}$ \\
\hline \multicolumn{9}{|l|}{ Pre-knowledge } \\
\hline $\operatorname{Sex}(F=1, M=2)$ & -.06 & & & & & & & \\
\hline Interest $\mathrm{T} 1$ & .16 & -.01 & & & & & & \\
\hline Self-Efficacy T2 & .12 & .01 & .46 & & & & & \\
\hline Self-Efficacy T3 & .19 & .00 & .42 & .59 & & & & \\
\hline Self-Efficacy T4 & .17 & .00 & .41 & .54 & .60 & & & \\
\hline Interest T5 & .13 & -.03 & .49 & .51 & .52 & .64 & & \\
\hline $\begin{array}{l}\text { Post-Knowledge } \\
\text { E-learning }\end{array}$ & .49 & .00 & .11 & .15 & .22 & .16 & .13 & \\
\hline Completion & .21 & -.01 & -.01 & .039 & .067 & .011 & -.01 & .13 \\
\hline Mean & 4.42 & & 4.61 & 4.40 & 4.35 & 4.38 & 4.43 & 5.84 \\
\hline SD & 2.03 & & 1.43 & 1.33 & 1.34 & 1.39 & 1.38 & 2.05 \\
\hline Cronbach's Alpha & & & .89 & .90 & .92 & .93 & .93 & \\
\hline
\end{tabular}

notes: Self-ef = Self-efficacy; all correlations $>.05$ are significant at $p<.05$; pre-post knowledge was on a scale of 1-10. 


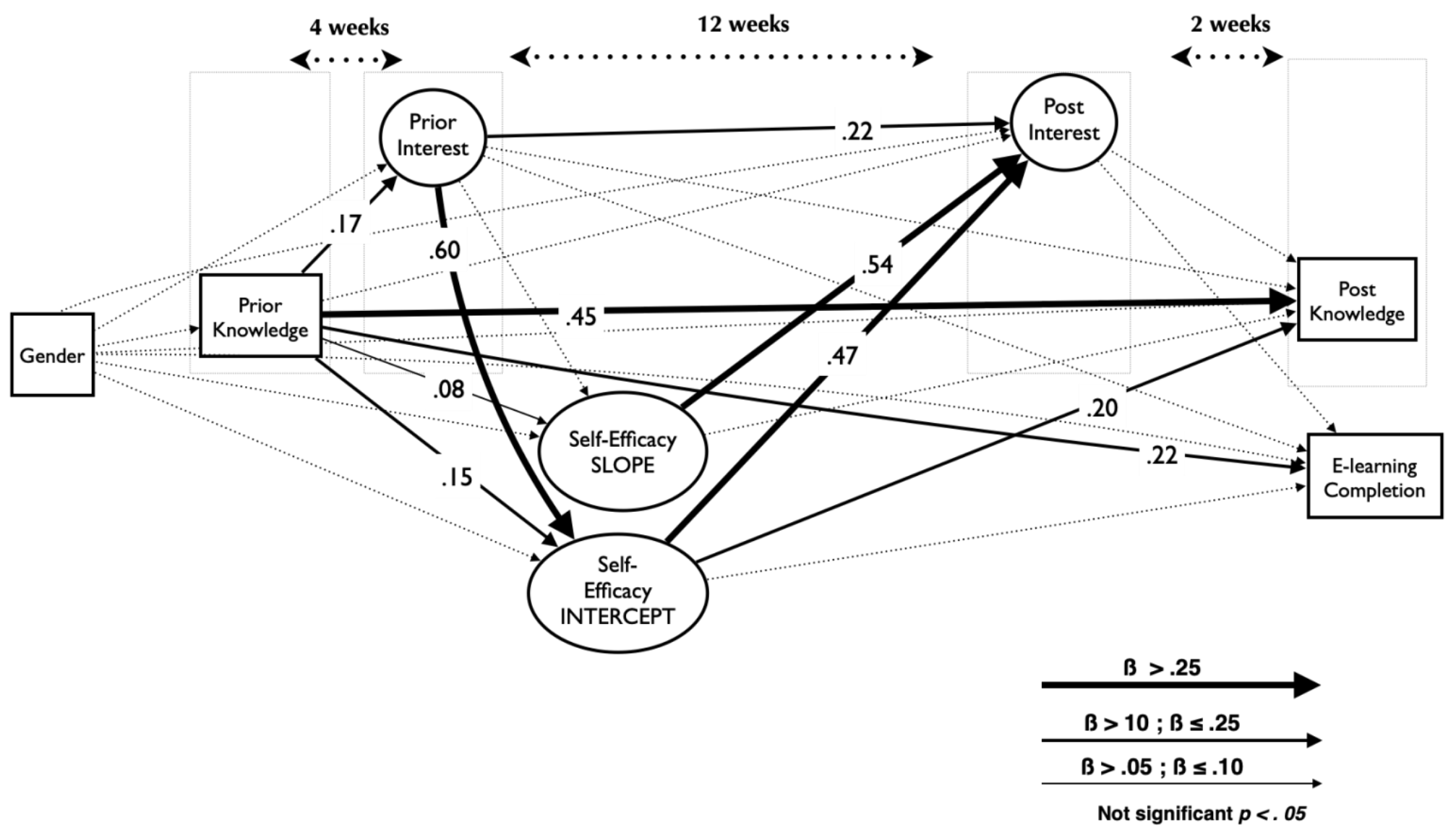

Figure 2. Latent trajectories predicting post individual interest and knowledge 
11 Appendix

Figure 2. Overview of the study's research design

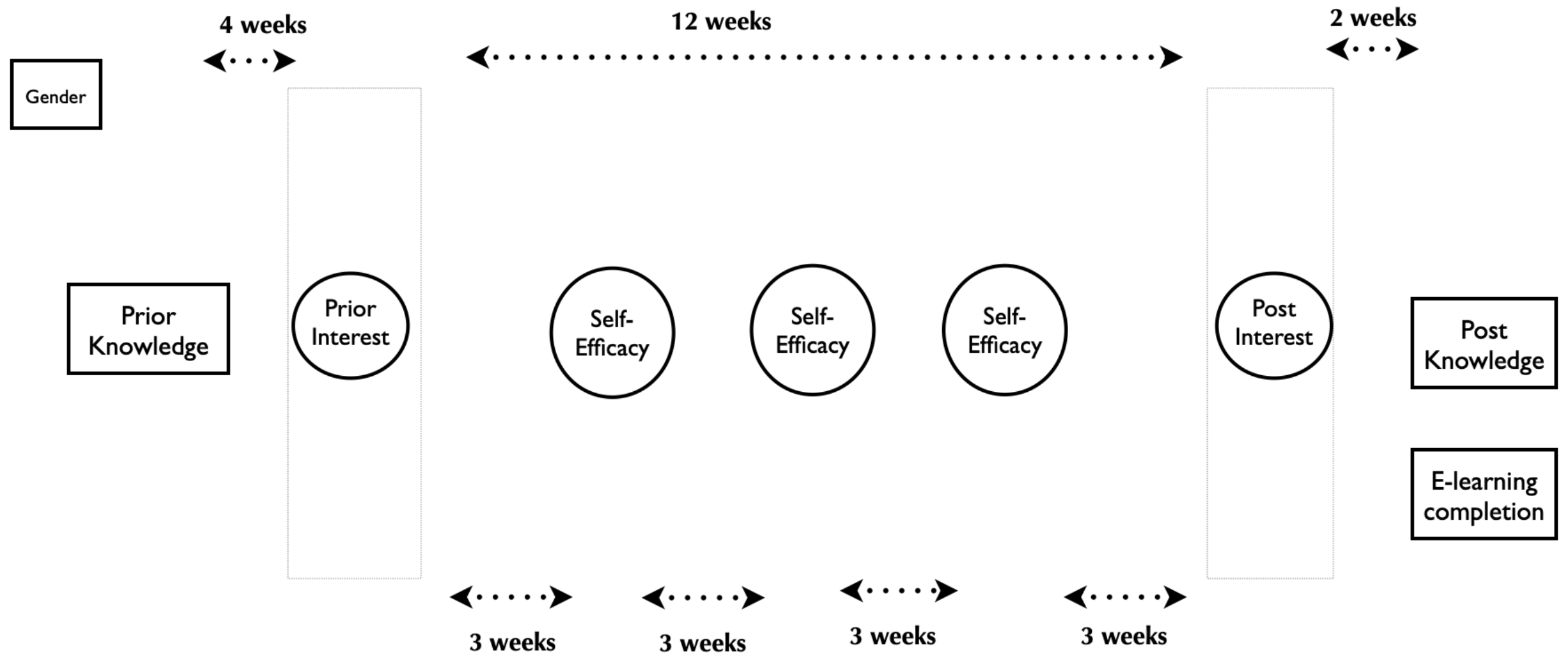


Table 1. All survey items in original Japanese with English translation

\section{Individual Interest:}

1. 英語はいつも面白いと考えている。

2. 今年、英語の学習を好きになりたいと思っている。

3. 興味が湧くだろうと思っている。

4.いつも英語をより多く学習したいと考えている。

1. I always consider English to be interesting.

2. This year, I want to develop an interest in learning English.

3. I am sure I will become more interested.

4. I am always looking to learn more English.

\section{Course Self-efficacy}

Scale Stem: 今年の英語の授業について答えてください。

1. 今年、授業で教わる技能を習得することができると確信している。

2. 最も難しい授業の学習方法が分かると確信している。

3.たとえ勉強が大変でも習得できる。

4. やりさえすれば、この授業の最も難しい勉強でもついていくことができる。

5. もし、あきらめなければ、授業でほとんどすべての勉強についていくことができる。

Stem: Please answer in regards to your English classes this year.

1. I am confident that I will be able to master the skills taught in class this year.

2. I am certain I can figure out how to do the most difficult class work.

3. I am confident that I can learn, even if the work is hard.

4. I am sure that I can keep up with the hardest parts of this class if I just do it.

5. As long as I don't give up, I can keep up with almost everything in class. 
Table 4. Unconditional Latent Curve Tests

\begin{tabular}{lll}
\hline & $\begin{array}{l}\text { Unconditional-self-efficacy } \\
\text { (intercept only) }\end{array}$ & $\begin{array}{l}\text { Unconditional SI-self-efficacy } \\
\text { (Slope and Intercept) }\end{array}$ \\
\hline CFI & 0.925 & 0.993 \\
TLI & 0.944 & 0.991 \\
RMSEA (90\% C.I.) & $.065(.048-.083)$ & $0.026(0-.053)$ \\
SRMR & 0.096 & 0.038 \\
Chi-Square & $47.282(8)$ & $8.889(5)$ \\
\hline
\end{tabular}

